\title{
My love affair with grounded theory - making the passion work in the "real" world
}

\begin{abstract}
Grounded theory offers the interpretive researcher a cornucopia of possibilities. Thanks to its theory-generating ethos, grounded theory is open and flexible and applicable to a variety of research settings. Furthermore, it can be used as a method, a framework, an analytical tool, and a paradigm. For the purposes of inductive research, grounded theory is very alluring and many qualitative scholars fall for its theory-building promise. Few, however, embrace the paradigm for all that it has to offer, despite claiming to being grounded in their approach to generating theory. Here I share my own passion for grounded theory: from the epistemological journey that led me to the paradigm, to pragmatically applying the method to my own research. Grounded theory is best equipped for furthering our understanding of complex social phenomena, providing us with the tools to generate rich, innovative data-driven theory, making our adoption of the method a truly lovely affair.
\end{abstract}

\section{Introduction}

There is an inherent sexiness to grounded theory (GT): its openness and flexibility; its theory- generating capabilities; its versatility for being a method, a technique, a framework, a paradigm, all rolled into one; its promise to "discover" something refreshingly new in unchartered territory; and its capacity to transform the mere mortal researcher into a theoretical conquistador of his or her data. GT's amorphousness gives the impression of simplicity, inferring that anyone anywhere could (potentially) be adopting the method. If we consider the nuts and bolts of GT to be "the discovery of emerging patterns in data" (Glaser, in Walsh et al. 2015:593) as argued by founding father Barney Glaser, then it would appear that in fact "everybody engages in GT every day because it's a very simple human process to figure out patterns and to act in response to those patterns" (p. 593), making the paradigm seem quite effortless in its application. Coupled with its broad applicability, the paradigm appears to be fearless in its defiant reaction to "the extreme positivism that had permeated most social research" (Suddaby 2006:633). In its origins, GT aimed to fill the "embarrassing gap" (Gibson and Hartman 2014:1) between theory and empirical research calling for a method that related more closely to the field under study. Instead of forcing "pet ideas" onto data, the grounded theorist should discover fresh, new theory from their context. Rugged and brave, GT has real (sex) appeal for the inductively inclined social scientist.

Its seductiveness, however, can be misleading, and although many claim to be grounded in their approach to generating theory, few in fact embrace the paradigm for all that it is. Like a fling, many are instantly attracted to its theory-building promise, yet few are willing to put in the blood, sweat, and tears needed to make the relationship work in the long run. Suddaby (2006) bemoaned that when researchers are pushed to expand on how their manuscript allegedly applies GT as a method, "it becomes clear that the term 'grounded theory' was interpreted to mean 'anything goes,"' meaning that the research "either ignored or deliberately violated the core procedures and tenets" (p. 640) of the methodology (see also Locke 1996). As reviewers ourselves, we come across many brash allegations of GT research projects, when in fact there is little of the paradigm to be found in the work itself: Gaps are filled, hypotheses are tested, interviews are premeditated in 
number and tightly structured in format, even the voice of the researcher is carelessly muted, yet there is a reckless claim of being "grounded" in the theory that is being generated from the data. The freedom that the paradigm offers is often mistaken for an easy ride.

Like other qualitative approaches, GT has a bad reputation in the field, where numbers over words are seen to have more validity and transferability. However, numbers may not always tell the best possible story, and social scientists should avoid being seduced by quantifiable data. Or as Einstein put it, "not everything that can be counted counts, and not everything that counts can be counted" (cited in Gioia, Corley, and Hamilton 2012:16). The process behind the method of theory generation is also quite different. Rather than assuming a linear, deductive approach, where theory is deduced and tested from a priori assumptions, using hypotheses and generalizing cause-and-effect relationships (Glaser and Strauss 1967), grounded theorists-as inductive researchers-express an idiographic knowledge in the form of working hypotheses, which is transient and contextual (Lincoln 1990). Qualitative research is regularly criticized for potentially providing "insightful empirical generalizations, but little theory" (Bryman and Bell 2003:12), where the only generalization plausible is the lack of a generalization, meaning that those adopting an inductive approach to theory generation are met with skepticism in their ability to generate persuasive new theories based on their "rather thin evidence" (Gioia et al. 2012:18). On the challenges of demonstrating rigor in the process of data collection, data analysis, and finally presentation of data-driven findings, qualitative researchers-including grounded theorists-are expected to go the extra mile in justifying their methodological approach, unpacking the process in a systematic manner, and making their respondents the protagonists of the study. In the second half of this review of GT, I provide some examples of how the researcher can overcome such obstacles and tackle (face on) the biases that continue to haunt our field of interpretive research ${ }^{1}$.

Like any great love story, GT also has its fair share of drama, where an irreparable quarrel broke its founding fathers into two competing schools of thought, where one favored "creativity and openness to unanticipated interpretations of data" (Suddaby 2006:638), while the other advocated for prescriptive coding and analysis. Some 50 years since Barney Glaser and Anselm Strauss first published The Discovery back in 1967, GT continues to be an incredibly enticing methodology for qualitative researchers across the board.

Although Discovery continues to be cited ad nauseam, there remains little consideration for key works that came after this capolavoro. Discovery is a beautifully composed prelude to a research methodology that was later unpacked by its authors (split as they were into two discernible approaches) and others that came after them: More than a how-to guide to GT, Discovery is a must- read taster for anyone claiming to be grounded in their data but is far from a practical manual to enabling the method as such $^{2}$ If researchers do little more than read Discovery as lightly acknowledging the

\footnotetext{
${ }^{1}$ As Gioia et al. (2012) bluntly put it, qualitative researchers continue to face scientific skepticism in the field, with heart-wrenching feedback such as "Great story! Good writing! Incisive thinking! But how do we know you haven't just made up an interesting interpretation" (p. 18).

2 Classic GT, as presented in Discovery, "is not a qualitative research methodology but rather a general methodology for the development of theory using any and all types of data" (Walsh et al. 2015:585; Glaser and Strauss 1967). Gibson and Hartman (2014) argued that Discovery "would never be a set of clearly defined 'procedures and definitions' [but rather] part argument, part presentation of [Glaser and Strauss's] approach rather than what they perceive as the outcome of the approach" (p. 28).
} 
paradigm (Locke 1996), they not only miss out on a wonderfully rich body of work that has unpacked the method and put GT into practice but also approach their data collection, data analysis, and data presentation in an unconvincing and methodologically weak manner, demonstrating a limited understanding of the paradigm itself. Fernandez, in Walsh et al. (2015), warned how "limited reading can, and often does, induce a risky sense of competence" (p. 587). The "all is data" dictum is easily abused, meaning that careless yet abundant presentation of data does not count as GT. Raw data do not speak for themselves, and it is the task of the researcher to lift them up to a theoretical realm. Interpretive researchers must also prove that their selection of data is kosher and that this selection has been done in a systematic way, meaning that the researcher has not simply "cherry picked the quotes ... contrived some clever explanation, and slapped a sexy label on it" (Gioia et al. 2012:18).

To appreciate the full package of what GT entails, we should familiarize ourselves with (among others) Glaser's Theoretical Sensitivity (1978) along with his proliferation of the method (1992, 1998, 2001, 2007, to name but a few), Strauss and Corbin's (1990) procedures and techniques, Charmaz's (2000, 2002, 2005, 2006, 2014) brilliant development of constructivist GT, Birks and Mills's (2011) practical guide, Goulding's (2002) insightful application of GT to organizational studies and marketing, and Gibson and Hartman's (2014) "rediscovery" of the method and comprehensive overview of current debates on the paradigm, as well as editorial pieces positioning GT within specific fields, such as Suddaby's (2006) clarification of what GT is not, Gioia and Pitre's (1990) work on theory building, and Gephart's (2004) nutshell on qualitative methods for management studies.

In the simplest of terms, GT extracts theory "from the ground up" (Langley 1999:691), focusing on the perspective of those in the field and how they go about meaning making and problem solving (Gibson and Hartman 2014). It is based on the principles of emergence, theoretical sampling, and constant comparison. Those who adopt GT should remain "open to what is discovered empirically in the area under study" (Walsh et al. 2015:586); carry out data collection, data coding, and analysis iteratively throughout the research process so as to make careful and conscientious choices as to which data to collect next in the theory-generating journey; and be able to continuously compare the data in search for similarities and differences. On the issue of openness, which should "cascade throughout the research process" (Gibson and Hartman 2014:35), Gioia and Thomas's (1996) study on organizational theory offers a compelling example of the benefits of remaining open in the gathering of data. When interviewing managers in an academic institution, they purposefully avoided using categorical terms such as threats and opportunities in their interview process; instead, terms such as strategic and political were brought up repeatedly by their respondents, which led the study down a theoretically and refreshingly new path. Had they designed their interview protocol "around existing theory and terminology" (Gioia et al. 2012:17) and inadvertently forced prior constructs onto their participants during the interview process itself, they would have missed out on this "key aspect of their sensemaking" (p. 17) in the workplace. Gibson and Hartman (2014) provided another vivid example in their smokers analogy: A study that goes into the field wishing to explore, for instance, "What coping strategies do smokers use when they are confronted with the stigma of social restrictions on smoking?" will be limited, in the eyes of GT, by preconceptions regarding smoking as being problematic, stigmatizing, and something smokers have to cope with. Remaining open not only encourages new, unexplored areas of research to emerge but also allows the researcher to foreground their participants (and the juicy data they provide), treating 
them as knowledgeable agents whose voices matter immensely in our discovery of new theory (Gioia et al. 2012). Going back to the smokers, we see how research questions or objectives can stifle a study from the onset just in the way they are worded.

Thanks to its inductive approach and cyclical nature to data collection, data analysis, and theory generation, GT is naturally messy: Theories are not neatly tested (or negated) in the field but rather unearthed with considerable amount of trial and error. In fact, papers adopting GT would rarely fit the standards of many top-tier journals, in which linearity and clarity of method are preferred, making the applicability of the paradigm all the more challenging. I, too, have struggled with molding my own GT underpinnings with the strictures of journal publication, having to tailor my methodology and select elements of the method that best suited my overall qualitative research.

In this brief article I share my own love story with GT and how I have tried, over the years, to shift my lustful infatuation for the paradigm to a more mature, committed, and rewarding long-term relationship. To my mind, GT, above all the rest, is a paradigm that helps further our understanding of social phenomena and provides us with the tools to really generate rich, innovative data-driven theory. Like in any relationship, I have been through my ups and downs with the method, fluctuating from the honeymoon period to the unavoidable domestic squabbles, especially when it comes to presenting my methodological approach in top-tier journals. Knowing how and when to use which specific elements of GT not only furthers our understanding of the paradigm itself (and all it can do for our research) but also helps us become more confident when presenting (and justifying) our methodological standpoint.

In sharing my (love) story with GT, I first consider the epistemological journey that led me to the paradigm, followed by a consideration of the benefits of the method and how it is applied to the "real" world of academic publishing. In telling this tale and from my own experience as an interpretive researcher and a constructivist at heart, I argue that GT has not yet reached its full potential as a research paradigm despite its half-a-century presence in the field. Here, I call for a stronger commitment on part of researchers and greater acceptance on part of reviewers to embrace GT for all that it has to offer, to go beyond carelessly citing Discovery and ignoring most of the rest, for the inclusion of GT in core methodology seminars, and for taking the brave leap into the field to build new and exciting theory that is genuinely data driven.

\section{Paradigms Lost-In Search of a Suitable Methodological Partner}

Although most research is initially triggered by benign curiosity or "puzzling over realworld phenomena or contexts" (Figueiredo, Gopaldas, and Fischer 2016:297), determining how to go about exploring these real-world phenomena is crucial. Given that GT is interpretive in nature, Birks and Mills (2011) argued that the researcher must first discern a personal position by asking ourselves some key questions prior to embarking on the (long-haul) research journey: How do we define ourselves as researchers? What is our ontological perspective? What is the relationship between the researcher and the researched? And do we go about gaining knowledge of the world around us? Asking ourselves these kinds of questions will help our research journey in the long run.

Before falling head over heels for GT, I first needed to filter out unsuitable ontological and epistemological candidates, and Guba's (1990) seminal work helped immensely in this filtering process. Selecting one's methodological partner can be laborious and timeconsuming, yet immensely satisfying once the researcher identifies a paradigm that underpins the research project as much as it does the researcher, making this paradigmatic choice a lifelong commitment (Rodner 2015). Suddaby (2006:639) argued 
that only when we are aware of our own epistemological position and philosophical underpinnings can we convincingly present our chosen methodology as the most suitable approach to the social phenomena under study. A quick overview of key ontological and epistemological assumptions convinced me that constructivism was the most suitable approach to unpacking the social phenomena under study, and it was through constructivism that I eventually became acquainted with my preferred suitor-GT. Underpinned by constructivism, which argues that social realities are constructed in the minds of individuals and groups (Guba 1990), my research could be enabled only with GT methods of data collection and analysis. Thanks to GT, I was able to uncover the social realities of my participants, immerse myself fully in the field, unravel the complexities of the subject under study, and embrace the necessary research qualities, where reflexivity, openness, flexibility, and the role of the researcher as a "passionate participant" all play a vital role in shaping the overall research project.

Considering the other prospective candidates, positivism, underpinned by a scientific method and a realist ontology, argues for the existence of "a reality out there, driven by immutable natural laws" (Guba 1990:19; see also Charmaz 2006; Lincoln 1990; Lincoln and Guba 2013; Schwandt 1990; Searle 1995). Positivists feel that this "scientific method ... can and should be extended to the study of human mental and social life [in order] to establish these disciplines as social sciences" (Benton and Craib 2011:23). Theories on this reality are tried and tested via hypotheses that help the positivist researcher develop laws and absolute truths about the real world (Flick 2007). To ensure a reliable analysis and understanding of this reality, the researcher adopts the necessary research methods that avoid any "human contamination" (Lincoln and Guba 2000:176). This contamination, or "leakage from their own personal involvement" (Burr 2003:151), comes from the researchers' inherited social, cultural, and historical biases, which are regarded by positivists as "extrascientific and hence irrelevant to any valid epistemological account of what constitutes genuine scientific knowledge and justification" (Schwandt 2000:196) and should therefore be avoided whenever possible. So, by following a realist ontology and an objectivist epistemology, the value-free inquirer is able to watch reality through a one-way glass, observing and analyzing nature without altering or contaminating it in any way. From an ontological perspective, this positivist belief that knowledge can be summarized in context-free generalizations sits uncomfortably with me as an individual as well as a researcher, making it an unsuitable suitor. And so I moved on to Guba's (1990) next candidate.

Reacting against the dominance of positivism, sociologists and historians of the nineteenth and twentieth centuries argued that human sciences, unlike natural sciences, called for a completely different process of interpretation to enable a deeper understanding of social phenomena (Schwandt 2000). Critical theorists believe in an objective external reality: If common man appears to be in a state of false consciousness, then critical theory aims to achieve true consciousness by adopting given values and transforming the world around them. Reality, for critical theorists, is shaped by social, political, cultural, economic, ethnic, and gender values that crystalize over time (Denzin and Lincoln 2005; Lincoln and Guba 2000; Popkewitz 1990). In practice, the researcher, becomes a central figure in the research process and uses qualitative methods and interpretive approaches to develop theory rather than test it: Taking a bottom-up perspective, the researcher's analysis of social phenomena and practices will in turn mold the theory (Flick 2007; see also Charmaz 2006). Although critical theory (and similar ideological movements) appears to be a more suitable match for my field of research than 
the scientific method favored by positivism, it is constructivism that best shaped the epistemological, ontological, and methodological perspectives of my field of research.

\section{Making Meaning Together-A Match Made in Heaven}

Constructivism, or social constructionism, as a school of thought traces its origins to postmodern- ism, which was critical of taken-for-granted ways of understanding the world (Benton and Craib 2011; Burr 2003; Silverman 2010), stressing instead for a multifaceted, interpretive, situation-based vision of reality (Burr 2003:12). Berger and Luckmann's seminal work-The Social Construction of Reality of 1966-argues that human beings together create and then sustain all social phenomena through social practices, involving the three essential processes of externalization, objectivation, and internalization. The end result is that reality is at once constructed by the social practices of people (individuals and groups) while being experienced by these people as pregiven and fixed. Knowledge, therefore, is created through a subjective process whereby reality "exists only in the context of a mental framework (construct) for thinking about it" (Guba 1990:25). Unlike the realist approach adopted by positivists, constructivism challenges the naive assumption that there exists a totally independent external reality. "The universe does not exist 'out there' independent of us. We are inescapably involved in bringing about that which appears to be happening. We are not only observers, we are participators ... in making (the) past as well as the present and the future" (Wheeler, in Searle 1995:158)

Engaged in creating our own world, we make or construct our realities using concepts, models, or schemes to make sense of our social experiences (Schwandt 2000:197). Charmaz (2000) argues that constructivist GT3 in fact "recognizes the mutual creation of knowledge by the viewer and the viewed" (p. 510) and that "the 'discovered' reality arises from the interactive process and its temporal, cultural and structural contexts" (p. 524). Thanks to its interpretive approach to theory building and its willingness to get down and dirty with the data, GT becomes the perfect methodological mate for constructivism as a means of unearthing the social meanings, experiences, and problem-solving taking place in the chosen research context.

Himself a constructivist, Guba (1990) asserted how "knowledge is the outcome or consequence of human activity; knowledge is a human construction, never certifiable as ultimately true but problematic and ever changing" (p. 26). As a social phenomenon, the mental constructs (or what is known) are not developed in isolation or a social vacuum but rather against a backdrop of socially and culturally shared understandings, languages, and practices: “man's specific humanity and his sociality are inextricably intertwined. Homo sapiens is always, and in the same measure, homo socius" (Berger and Luckmann 1966:69). Never engaging in a sociohistorical vacuum, Burr (2003) observed how, as a social being, or Homo socius, one is necessarily born into a world that has already been constructed by previous generations:

Human beings continually construct the social world, which then becomes a reality to which they must respond. So that although human beings construct the social world they cannot construct it in any way they choose. At birth they enter a

\footnotetext{
${ }^{3}$ Highly interpretive and focused on linking constructs, constructivist GT takes on the added burden of describing "what is going on" in the field as well as exploring how individuals and groups construct their meanings and experiences of that world (Gibson and Hartman 2014).
} 
world already constructed by their predecessors and this world assumes the status of an objective reality for them and for later generations. (p. 185)

If one considers reality to be a socially constructed phenomenon, then the sociology of knowledge must analyze the processes in which this construction of reality takes place. The almighty Berger and Luckmann (1966) maintained that "an adequate understanding of the 'reality sui generis' of society requires an inquiry into the manner in which reality is constructed. This inquiry ... is the task of sociology of knowledge" (p. 30; see also Flick 2007; Silverman 2006) ${ }^{4}$. As a social phenomenon, this meaning or knowledge is not viewed as "something that a person has or doesn't have, but as something that people do together" (Burr 2003:9).

Taken a step further, GT as the research paradigm for discovery aims to unpack the relationships between various social phenomena, thereby acknowledging that the social world is organized around the problems people experience and that this organization can be unearthed from the data and subsequently conceptualized. The paradigm does not hope to abstract or approximate to a single reality but rather openly embraces "the presentation of multiple, holistic, competing, and often conflictual realities of multiple stakeholders and research participants" (Lincoln 1990:73), including the researchers. This participatory nature of the paradigm made it incredibly attractive to me, as I was encouraged to become part of the research process and embrace being a passionate participant of the study.

Ontologically with its relativist approach, epistemologically with its subjectivism, and methodologically with its hermeneutic and dialectic considerations, constructivism became an ideal bedfellow for me as a researcher. My leap from constructivism into GT was made through Charmaz's $(2000,2002,2005,2006,2014)$ immensely engaging work. Once I went grounded I could never go back, engaged as I was in shaping the research as much as I was discovering it.

\section{Becoming the Passionate Participant}

Previously, social sciences demanded that the inquirer "stand outside of time and context, and, indeed outside themselves as persons" (Lincoln 1990:70) to deliver credible and value-free research results. GT, however, takes a reflexive approach to the world under study not only by paying attention to the collected interpretations of the studied empirical realities but also by "locating oneself in these realities" (Charmaz 2005:509). Thanks to its interpretivist dictum, GT depends on the "sensitivity of [the] researcher" (Suddaby 2006:639) to unearth meanings and connotations from their immersion (if not drowning) in the data, demanding a "close and longstanding connection" (p. 640) between the researcher and the researched (see also Langley 1999; McCracken 1988). Regarding the passionate participant, Charmaz (2006) noted how

[w]e are not passive receptacles into which data are poured [so that] neither observer nor observed come to a scene untouched by the world. Researchers and research participants make assumptions about what is real, possess stocks of knowledge, occupy social statutes, and pursue purposes that influence their respective views and actions in the presence of each other. (p. 15)

\footnotetext{
${ }^{4}$ With this in mind, "people, institutions and interactions are involved in producing the realities in which they live and these productive efforts are based on processes of meaning-making" (Flick 2007:12; see also Crotty 1998; Lincoln and Guba 2000).
} 
In this sense, academic inquiry cannot be value free but rather molded by both parties from start to finish, making research a "co-production" (or "co-generation" of theory) between the researcher and the researched (Denzin and Lincoln 2005:21), meaning that we should be aware of our "position in the field" (Pratt 2009:859) and be willing to reflect about our position within the study (Burr 2003; Charmaz 2005; Gibson and Hartman 2014; Guba 1990; Schwandt 1990; Suddaby 2006). In sharp contrast to the objectivist ontology and value-free framework that underpins positivism (Denzin and Lincoln 2005), the interpretive researcher, as a human instrument within the research process, views objectivity as an impossibility, since "no human being can step outside their humanity" (Burr 2003:152). Ignoring our sociohistorical biases or cultural traditions of how we perceive our world would be as unfeasible as "trying to step outside of our own skins" (Gallagher, in Schwandt 2000:195).

As well as remaining firmly within one's humanness, the researcher acts as "facilitator of a multivoice reconstruction" (Lincoln and Guba 2000:166) of the subject under study, assuming, in this way, that one's own voice and that of the participants actively create meaning and should not be silenced or ignored (Silverman 2010:226). With this in mind, Fontana and Frey (2005) proposed a more emphatic approach when carrying out interviews so that the "interviewer becomes an advocate and partner in the study" ( $p$. 696), and hence "interviews are seen as negotiated accomplishments of both interviewers and respondents" (p. 716). By purposely rejecting neutrality as a desirable trait, the qualitative inquirer becomes involved in actively shaping the entire research process. Consequently, the narrative style, which best reflects this philosophical paradigm, would be the first person, suggesting that we as researchers actively participate in the construction and communication of the knowledge embodied in the study 5 , narrating as we do the story in a humanly, vivid, scholarly, analytic, and empathetic manner (Lincoln and Guba 2000:194). Given that any researcher must make editorial decisions as to which parts of data to use to tell their story, they should also consider those voices that have helped construct the study but have been unfortunately left out of the final narrative (Figueiredo et al. 2016). One way of honoring everyone's participation, and making the most of our rich data, is to use power and proof quotes to tell the whole story (Pratt 2008, 2009) ${ }^{6}$ so that the protagonists are kept within the main body of the text and the supporting cast members are compiled into a data table.

Along with a sympathetic voice, the researcher should adopt a chameleon-like gaze so as to minimize obtrusiveness and attempt to blend into the research context with minimal disruption (Schwandt 2000). As an unobtrusive "chameleon" of my field of research, I become an active listener and participant observer, conducting my ethnographies as a "mode of being in the world" (Atkinson and Hammersley, in Silverman 2006:68). This approach allows me to observe and record my participants in situ and embrace the social experience as closely to reality as possible. Beyond writing fieldnotes, my ethnographic data lead me to rich, subjective personal introspections or autoethnographies (Holbrook 1995, 2005, 2006; see also Wohfeil 2015). Beyond simple observation, conducting subjective personal introspections allows me to unpack what is "going on" in the field and how meanings are made by research participants. In my

\footnotetext{
${ }^{5}$ For Charmaz (2006) there is no need for a "silent authorship replete with assumed neutrality, objectivist pretentions, and an absent author" (pp. 174-175).

${ }^{6}$ Pratt (2009) suggested the use of power quotes to present the "most compelling" (p. 860) parts of the data, which effectively illustrate the main argument or theory, whereas proof quotes are used to "bolster points you have already made in the body of the paper" (p. 860).
} 
Accepted for publication in Sociological Focus published by Taylor \& Francis

(C) Victoria L. Rodner, 2019

particular field of consumer culture theory, through my auto-ethnography, I become the consumer.

\section{Making the Passion Work in the "Real" World-GT in Action}

Being many things at once, GT can be presented as a holistic or selective method. As we have seen already, few studies embrace the paradigm for all that it is, and many researchers in fact "cherry-pick" what they find most suitable for their own research output (Walsh et al. 2015). However deep one goes into GT, we should present our use of the method with the utmost clarity and rigor.

First and foremost, when adopting a grounded approach, one must be iterative in data collection, data analysis, and data presentation so as to allow for a free and enriching flow between raw data, the emerging themes, and the relevant literature that will shape the overall study. As well as being open to see social phenomena through the eyes of our participants, we should also remain open to the emerging theoretical constructs or adopt what Glaser (1978) termed theoretical sensitivity. Although this openness may sound incredibly seductive, it can be excruciatingly painful in practice: hours, days, weeks, months, even years of work may swiftly be written off in favor of a more enticing discovery that has been made in the data.

The myth that the researcher comes into the field with an empty head is just that, a myth. An open mind does not necessarily mean an empty one. In fact, every researcher comes into a research context with some sort of conceptual framework, which helps him or her "very loosely explore the structure and processes in the situations to be studied" (Gibson and Hartman 2014:34). However, if the researcher wishes to embrace GT's signature openness, an openness that should in fact "cascade throughout the research process" (Gibson and Hartman 2014:35), he or she needs to be willing to sacrifice semicompleted work in exchange for richer, more paradigm-shifting material. From my own experience I have had to rewrite entire literature reviews, reconsider conceptual frameworks, and discard large chunks of my preliminary findings to embrace a much denser, more enticing, and scholarly relevant theoretical discovery made during the ongoing data collection and analysis process. Flexibility and openness lie at the heart of what it means to be grounded. Nevertheless, such openness could potentially suggest an endless (and purposeless) research journey, whereby the grounded theorist gets drawn deeper into data and further away from a single, cohesive story. Jane Hood suggested a corkscrew approach as a means of keeping a vigilant eye on the key emergent theory:

... tighten what I call the corkscrew or the hermeneutic spiral so that you end up with a theory that perfectly matches your data. Because you choose the next people to talk to or the next cases to find based upon the analysis and you don't waste your time with all sorts of things that have nothing to do with your developing theory. (in Charmaz 2006:101)

Once we have committed to GT's openness, we can then move on to examine which tools will enable us to collect and analyze the data for our study. How we sample, interview, code, and memo-write matters immensely.

When conducting quantitative research, sampling needs to be formalized so as to generate reliable, statistical generalizations on a much larger population. In qualitative research, where broader generalizations are generally avoided, sampling tends to follow quite a different logic altogether: With a theory-building approach to research, sampling is neither planned nor formalized but rather developed in the field and molded to best 
suit the overall data collection process (Flick 2007; Silverman 2010). With this in mind, Glaser and Strauss (1967) defined theoretical sampling as "the process of data collection for generating theory whereby the analyst jointly collects, codes, and analyzes his data and decides what data to collect next and where to find them, in order to develop his theory as it emerges" (p. 45). In sharp contrast to statistical (or random) sampling, theoretical (or purposive) sampling is carried out to "discover categories and their properties and to suggest interrelationships into a theory" (Glaser and Strauss 1967:62). For Charmaz (2006), theoretical sampling helps one narrow the focus on the categories that are emerging from the data while defining these categories, so that "theoretical sampling helps you to check, qualify, and elaborate the boundaries of your categories and to specify the relations among categories" (p. 107). Taken a step further, the researcher may also apply a respondent-driven sampling method, such as snowballing or nominated sampling, and ask participants to actively take part in introducing new candidates for the study (Hood 2012; Morse 2012).

Sampling technique goes hand in hand with sample size, which remains a thorny subject for qualitative researchers (Pratt 2009). In search of the magic number, Kvale (2007) suggested inter- viewing "as many subjects as necessary to find out what you need to know" (p. 43)-horribly vague advice for a crucial element of any research study. A small sample size will make it difficult for the researcher to draw substantiated conclusions and make theoretical generalizations, whereas a large sample size may prove too vast to ever achieve a thorough and convincing analysis of the issue under study. A useful rule of thumb is to stop data collecting once your categories reach "theoretical saturation"-or "completeness" in Glaser's (2001) terms-meaning that you perceive a "core cate- gory" emerging from the data that is able to integrate the overall analysis (Strauss and Corbin 1990; see also Charmaz 2006; Glaser and Strauss 1967; Silverman 2006). For Charmaz (2006), saturation is achieved when the data "no longer [spark] new theoretical insights" (p. 113). Suddaby (2006) acknowledged the messiness of GT for determining exactly when saturation has been achieved:

Because grounded theory research uses iteration and sets no discrete boundary between data collection and analysis, saturation is not always obvious, even to experienced researchers. ... Deciding saturation has happened takes tacit understanding, which is achieved as much through experience as through a priori criteria. (p. 639)

Armed with our sample, we must now unpack what is going on in the field. Apart from ethnographic participant observation in the field, as mentioned earlier, conducting interviews is a key tool in the data collection process. As a "powerful method of producing knowledge of the human situation" (Kvale 2007:9), the interview allows one to "step into the mind of another person, to see and experience the world as they do themselves" (McCracken 1988:9). As a means of storytelling, interviews are excellent exploration tools, whereby the researcher delves deep into the livelihoods of the research participants. A warning label should come with GT, where this full immersion in the field and in-depth interviewing can induce the "going native" syndrome where we become "too close and [adopt] the informant's view, thus losing the higher-level perspective necessary for informed theorizing" (Gioia et al. 2012:19). To avoid losing oneself completely in the field, we can triangulate our data by including multiple sources and relying on collaborative data gathering and analysis with our coauthors. 
Once data have been collected and transcribed, we must then embark on the arduous task of coding our material. Beyond mere diligent labelling of data, coding is a linking tool to couple raw, tangible data to the emergent theory so that, through coding, one starts to "define what is happening in the data and begin to grapple with what it means" (Charmaz 2006:46). As codes are used to summarize or condense large volumes of data, they help us coherently and consistently identify "patterns of action" (Saldaña 2009:5), patterns that in turn construct a skeletal framework of the data collected in the field ${ }^{7}$. In this sense, coding "generates the bones of your analysis. Theoretical integration will assemble these bones into a working skeleton. Thus, coding is more than a beginning, it shapes an analytic frame from which you build the analysis" (Charmaz 2006:45).

Theoretical coding provides a deeper understanding of the issue and leads to the development of categories or themes, and subsequently to the development of datadriven theory. Charmaz (2006) suggested how coding should encourage the researcher to "play with the ideas" (p. 70) taken from the data in their search of a deeper understanding of the social phenomenon under study. Grounded theorists recommend several coding cycles (such as initial and focused, first and second, or initial and intermediate and all their subcategory-offspring) as ways of filtering through the data and eventually reaching the much-desirable core category. First-cycle methods are relatively simple, direct, and open (Strauss and Corbin 1998), whereas second-cycle coding necessitates deeper analytical skills to classify, prioritize, integrate, synthesize, abstract, conceptualize, and eventually build theory from the data. In search of a "coherent synthesis of the data corpus" (Saldaña 2009:149) during the coding analysis, I personally prefer axial coding as a means to "reassemble fractured data" (Charmaz 2006:60) and make connections between categories "to give coherence to the emerging analysis" (Charmaz 2006:60; see also Bryant and Charmaz 2012; Strauss and Corbin $1990,1998)$. By relating these various categories together, one ends up with a core category, central issue, or an axis that becomes the storyline that essentially ties the research together.

Codes are fine and dandy but weaving them into a cohesive (publishable) story is what brings home the bacon. This is where GT's secret weapon comes in handy: memo-writing. As a means of "cutting new analytical paths" (Charmaz 2006:72) through our findings, Charmaz (2006) saw memo- writing as the "pivotal intermediate step between data collection and writing draft papers" and suggested doing continuous memo-writing throughout the analytic phase to help trigger "progressively stronger, clearer, and more theoretical" analysis of the subject under study (p. 115).

For Saldaña (2009), code-weaving is what helps integrate codes into narrative form and "see how the puzzle fits together" (p. 187). Like memo-writing, code-weaving leads to a deeper exploration of new meanings and potential interactions between major codes identified in the analysis. Therefore, the purpose of these memos (or woven codes) is to take a break from an often tedious coding process; to document and think about the process itself along with the codes one has developed so far; and to determine which categories, themes, and concepts are giving the study shape. By writing memos I am able to remain more involved in the analysis of my emergent themes and became more fluent

\footnotetext{
${ }^{7}$ Gioia et al. (2012) elaborated on this analogy further in that "if the data structure is the anatomy of the coming theory, then the grounded model is the physiology of that theory. The writing in the GT section articulates and weaves together the workings of this anatomy and physiology to produce a dynamic inductive model that describes or explains the processes and phenomena under investigation" (p. 24).
} 
in abstracting ideas ${ }^{8}$ so that memo-writing encourages our minds to "rove freely in, around, under, and from the category; and write whatever comes to [us]" (Charmaz 2006:81). Along with this idea of wandering freely through the data, we grounded theorists should use memo-writing to jot down our initial thoughts in an informal and playful manner:

Memo-writing frees you to explore your ideas about your categories. Treat memos as partial, preliminary, and provisional. Writing memos quickly without editing them fosters developing and preserving your natural voice. Then your memo reads as though written by a living, thinking, feeling human being rather than a pedantic social scientist. (p. 84)

Bravo Kathy [Charmaz]! You have saved us from writing like pedantic social scientists and openly encouraged us to embrace our naturally creative, interpretive voice. We are, after all, writers in this world of academia. If I were not already enamored with GT, discovering memo-writing was simply orgasmic.

Last, and to wrap up this introduction on doing GT, we need to consider how to best present our grounded research in a publishable format. Even if GT is conducted iteratively, meaning that data are collected and analyzed simultaneously, its findings need to be presented sequentially: "In pure form, grounded theory research would be presented as a jumble of literature consultation, data collection, and analysis conducted in ongoing iterations that produce mainly relatively fuzzy categories that, over time, reduce to fewer, clearer conceptual structures" (Suddaby 2006:637). Given that jumbled parts of literature and fuzzy categories are unacceptable in most publication outlets, the researcher needs to clearly justify and illustrate their research journey in a coherent and sequential format for the benefit of the reader. When writing up our findings, Flick (2007) suggested that as researchers we should "make transparent how we proceed and how we arrived at our findings and conclusions" (p. 66), demonstrating how we lifted our data into theoretical concepts. Grounded theorists argue that one way of achieving this transparency of our research journey is by diagraming our codes-to-theory journey as a means of walking the reader through our thought process with relative ease and speed, not to mention helping ourselves in the development of codes, themes, and categories that all hang together for the creation of data-driven theory. Saldaña's (2009) codes-totheory model for qualitative inquiry (Figure 1) is an immensely useful template on which to work, as it allows the researcher to map their theory-building process, moving as they do from tangible codes to generalizable theory.9 Similarly, Corley and Gioia's (2004) data structure captures visually the first-order concepts, second-order themes, and aggregate dimensions in a clear and cohesive illustration of the data process. Pratt (2009) stated how diagramming data can in fact help illustrate how the "methodological process unfolded [showing visually] how you moved from raw data to the theoretical labels or constructs you are using to represent that data" (p. 860). By illustrating "how we progressed from raw data to terms and themes in conducting analyses" (Gioia et al. 2012:20), we demonstrate the all-important rigor of our research. Don't get me wrong: this step of visualizing the data process is no walk in the park. It is the seven-year itch that makes or breaks the relationship. Getting through it is a monumental achievement

\footnotetext{
${ }^{8}$ Saldaña (2009) suggested applying the "touch test" when writing memos from tangible codes: from a "real" or "touchable" code such as "mother," we should find its abstract equivalent, that is, "motherhood," which will then be used throughout the analysis stage of the research (p. 187).
} 
and should not be taken lightly. However, once the researcher is on the other side of this particularly challenging obstacle, it is smooth sailing into the writing stages of the study.

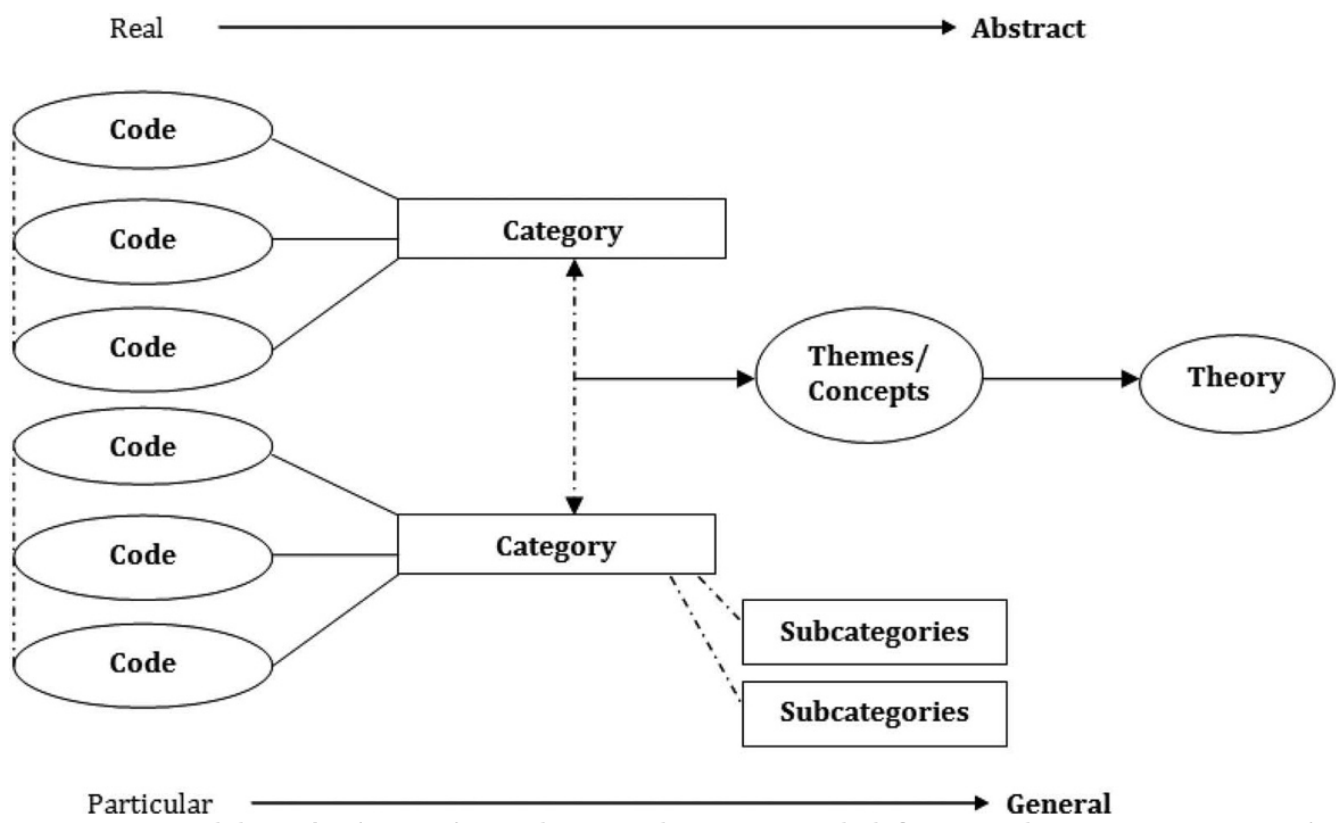

Figure 1. Saldaña's (2009) Code-to-Theory Model for Qualitative Inquiry (p. 12).

As well as presenting our story visually, we must also tell our full story verbally. With this in mind, interpretive case studies lend themselves well to GT research in that they aim to "make a lot out of a little" (Silverman 2010:137) and allow the researcher to delve in thick description of the social phenomenon under study. On the transferability of the case study, Lincoln and Guba (2013) stressed that it "provides the thick description needed to apprehend, appreciate, and understand the circumstances of the setting, including, most importantly, its physical, social, economic, and cultural elements" (p. 80; on case studies see also Denzin and Lincoln 2005; Eisenhardt 1989; Eisenhardt and Graebner 2007; Kvale 2007; Stake 2000, 2005; and, of course, Glaser and Strauss 1967).

Now that we are well acquainted with GT, with its paradigmatic underpinnings and its methods, with its philosophy and practicalities, with its benefits and with its flaws, we must now decide if we wish to commit to the paradigm and live happily ever after.

\section{Conclusion-For Better or for Worse, in Sickness and in Health}

Classic GT, as presented in Glaser and Strauss's Discovery advocates for a "just do it" mantra, meaning that "[y]ou should just get on with your research, and when you do it you will see that the most amazing theories will emerge. If bogged down in philosophical discussions, you will be less productive, less sensitive to what goes on in a social setting, and no theory will emerge" (Gibson and Hartman 2014:17). For many, this mantra of "just doing it" will seem too risky to even consider seriously. To my mind, the beauty behind GT is the holistic growth process of the method itself: Curious about a particular social phenomena, the brave researcher takes their first steps into the field and thanks to GT's openness, is encouraged to collect, analyze and interpret data with fresh and reflective eyes. From our initial exposure to the chosen research setting, we start to carve out themes of scholarly interest and identify pertinent fields of literature. This is then followed by a deeper immersion in the field and further exploration of the data to uncover 
more empirical material. Coming up for air from the field, the researcher will have more data to analyze that will either complement or shift the theoretical framework altogether. Like no other paradigm, GT allows researchers to be the master of their data, the captain of their theory, and this is what I find incredibly alluring. From my brief overview of the theory and workings of the paradigm, I can suggest no other methodology that is as fulfilling, enriching, or satisfying for the interpretive researcher. For anyone enticed to give it a go, I suggest Glaser and Strauss's (1967) Discovery as an amuse-bouche of the paradigm, a way to wet their palette, followed by some of the excellent work that I have referenced here, which offers those all-important tools on how to make GT work in the "real" world. Now coupled with your paradigmatic life partner, I encourage you-the researcher-to dive headfirst into the field and let the data show you the way: With GT by your side, only happy endings are in store. 
Accepted for publication in Sociological Focus published by Taylor \& Francis

(C) Victoria L. Rodner, 2019

\section{References}

Benton, Ted and Ian Craib. 2011. Philosophy of Social Science: The Philosophical Foundations of Social Thought. Basingstoke, UK: Palgrave Macmillan.

Berger, Peter and Thomas Luckmann. 1966. The Social Construction of Reality: A Treatise of Sociology of Knowledge. London, UK: Penguin Books.

Birks, Melanie and Jane Mills. 2011. Grounded Theory-A Practical Guide. London, UK: Sage.

Bryant, Anthony and Kathy Charmaz, eds. 2012. The SAGE Handbook of Grounded Theory. London, UK: Sage. Bryman, Alan and Emma Bell. 2003. Business Research Methods. Oxford, UK: Oxford University Press.

Burr, Vivien. 2003. Social Constructionism. London, UK: Routledge.

Charmaz, Kathy. 2000. "Constructivist and Objectives Grounded Theory Analysis." Pp. 509-35 in Handbook of Qualitative Research, 2nd ed., edited by Norman K. Denzin and Yvonne S. Lincoln. Thousand Oaks, CA: Sage.

Charmaz, Kathy. 2002. "Grounded Theory: Methodology and Theory Construction." Pp. 6396-99 in International Encyclopedia of the Social and Behavioral Sciences, edited by Neil J. Smelser and Paul B. Baltes. Amsterdam: Pergamon,

Charmaz, Kathy. 2005. "Grounded Theory in the 21st Century: Applications for Advancing Social Justice Studies.” Pp. 507-36. in The SAGE Handbook of Qualitative Research, 3rd ed., edited by Norman K. Denzin and Yvonne S. Lincoln. London, UK: Sage.

Charmaz, Kathy. 2006. Constructing Grounded Theory-A Practical Guide through Qualitative Analysis. London, UK: Sage.

Charmaz, Kathy. 2014. Constructing Grounded Theory. 2nd ed. London, UK: Sage.

Corley, Kevin G. and Dennis A. Gioia. 2004. "Identity, Ambiguity and Change in the Wake of a Corporate Spin-Off." Administrative Science Quarterly 49 (2):173-208.

Crotty, Michael. 1998. The Foundations of Social Research: Meaning and Perspective in the Research Process. London, UK: Sage.

Denzin, Norman K. and Yvonne S. Lincoln, eds. 2005. The SAGE Handbook of Qualitative Research, 3rd ed. London, UK: Sage.

Eisenhardt, Kathleen M. 1989. "Building Theories from Case Study Research." Academy of Management Journal 14 (4):532-50.

Eisenhardt, Kathleen M. and Melissa E. Graebner. 2007. "Theory Building from Cases: Opportunities and Challenges." Academy of Management Journal 50(1):25-32. doi: 10.5465/amj.2007.24160888.

Figueiredo, Bernardo, Ahir Gopaldas, and Eileen Fischer. 2016. "The Construction of Qualitative Research Articles: A Conversation with Eileen Fischer." Consumption Markets \& Culture 20(4):297-305. doi: 10.1080/10253866.2016.1222658.

Flick, Uwe. 2007. Designing Qualitative Research. London, UK: Sage.

Fontana, Andrea and James H. Frey. 2005. "The Interview: From Neutral Science to Political Involvement." Pp. 695-728. in The SAGE Handbook of Qualitative Research, 3rd ed., edited by Norman K. Denzin and Yvonne S. Lincoln. London, UK: Sage.

Gephart, Robert P. 2004. "Qualitative Research and the Academy of Management Journal." Academy of Management Journal 47:454-62. doi: 10.5465/amj.2004.14438580.

Gibson, Barry and Jan Hartman. 2014. Rediscovering Grounded Theory. London, UK: Sage. Gioia, Dennis A., Kevin G. Corley, and Aimee L. Hamilton. 2012. "Seeking Qualitative Rigor in Inductive Research: Notes on the Gioia Methodology." Organizational Research Methods 16(1):15-31. doi: 10.1177/1094428112452151. 
Accepted for publication in Sociological Focus published by Taylor \& Francis

(C) Victoria L. Rodner, 2019

Gioia, Dennis A. and Evelyn Pitre. 1990. "Multiparadigm Perspectives on Theory Building." Academy of Management Review 15(4):584-602. doi: 10.5465/amr.1990.4310758.

Gioia, Dennis A. and James B. Thomas. 1996. "Identity, Image and Issue Interpretation: Sensemaking during Strategic Change in Academia." Administrative Science Quarterly 41(3):370-403. doi: 10.2307/2393936.

Glaser, Barney G. 1978. Theoretical Sensitivity: Advances in the Methodology of Grounded Theory. Mill Valley, CA: Sociology Press.

Glaser, Barney G. 1992. Emergence versus Forcing: Basics of Grounded Theory Analysis. Mill Valley, CA: Sociology Press.

Glaser, Barney G. 1998. Doing Grounded Theory: Issues and Discussions. Mill Valley, CA: Sociology Press.

Glaser, Barney G. 2001. The Grounded Theory Perspective: Conceptualization Contrasted with Description. Mill Valley, CA: Sociology Press.

Glaser, Barney G. 2007. Doing A Formal Theory: A Proposal. Mill Valley, CA: Sociology Press.

Glaser, Barney G. and Anselm L. Strauss. 1967. The Discovery of Grounded Theory: Strategies for Qualitative Research. Piscataway, NJ: Aldine Transaction.

Goulding, Christina. 2002. Grounded Theory: A Practical Guide for Management, Business and Market Researchers. London, UK: Sage.

Guba, Egon G., ed. 1990. The Paradigm Dialog. London, UK: Sage.

Holbrook, Morris B. 1995. Consumer Research: Introspective Essays on the Study of Consumption. Thousand Oaks, CA: Sage.

Holbrook, Morris B. 2005. "Customer Value and Autoethnography: Subjective Personal Introspection and the Meanings of a Photograph Collection." Journal of Business Research 58(1):45-61. doi: 10.1016/S0148-2963(03)00079-1.

Holbrook, Morris B. 2006. "Consumer Experience, Customer Value and Subjective Personal Introspection: An Illustrative Photographic Essay." Journal of Business Research 59(4):714-25. doi: 10.1016/j.jbusres.2006.01.008.

Hood, Jane. 2012. "Orthodoxy Vs. Power: The Defining Traits of Grounded Theory." Pp. 151-64 in The SAGE Handbook of Grounded Theory, edited by Anthony Bryant and Kathy Charmaz. London, UK: Sage

Kvale, S. 2007. Doing Interviews. London, UK: Sage.

Langley, Ann. 1999. "Strategies for Theorizing from Process Data." Academy of Management Review 24:691-710. doi: 10.5465/amr.1999.2553248.

Lincoln, Yvonne S. 1990. "The Making of a Constructivist." Pp. 67-87 in The Paradigm Dialog, edited by Egon G. Guba. London, UK: Sage,

Lincoln, Yvonne S. and Egon G. Guba. 2000. "Paradigmatic Controversies, Contradictions, and Emerging Confluences." Pp. 163-88. in The SAGE Handbook of Qualitative Research, 2nd ed., edited by Norman K. Denzin and Yvonne S. Lincoln. London, UK: Sage.

Lincoln, Yvonne S. and Egon G. Guba. 2013. The Constructivist Credo. Walnut Creek, CA: Left Coast Press.

Locke, Karen. 1996. "Rewriting the Discovery of Grounded Theory after 25 Years?" Journal of Management Inquiry 5 (3):239-45. doi: 10.1177/105649269653008.

McCracken, Grant. 1988. The Long Interview. Qualitative Research Methods, vol. 13. London, UK: Sage Publications. 
Accepted for publication in Sociological Focus published by Taylor \& Francis

(C) Victoria L. Rodner, 2019

Morse, Janice. M. 2012. "Sampling in Grounded Theory." Pp. 229-44 in The SAGE Handbook of Grounded Theory, edited by Anthony Bryant and Kathy Charmaz. London, UK: Sage.

Popkewitz, Thomas S. 1990. "Whose Future? Whose Past? Notes on Critical Theory and Methodology." Pp. 46-66 in The Paradigm Dialog, edited by Egon G. Guba. London, UK: Sage.

Pratt, Michael G. 2008. "Fitting Oval Pegs into Round Holes: Tensions in Evaluating and Publishing Qualitative Research in Top-Tier North American Journals." Organizational Research Methods 11:481-509. doi: 10.1177/1094428107303349.

Pratt, Michael G. 2009. "For the Lack of a Boilerplate: Tips on Writing up (And Reviewing) Qualitative Research." Academy of Management Journal 52(5):856-62. doi: 10.5465/amj.2009.44632557.

Rodner, Victoria L. 2015. "Finding the Perfect Fit-Paradigmatic Choices for Novice and Experienced Qualitative Researchers." Symbolic Interaction 38(1):161-64. doi: 10.1002/symb.2015.38.issue-1.

Saldaña, Johnny. 2009. The Coding Manual for Qualitative Researchers. London, UK: Sage.

Schwandt, Thomas A. 2000. "Three Epistemological Stances for Qualitative Enquiry: Interpretivism, Hermeneutics, and Social Constructionism." Pp. 189-214. in The SAGE Handbook of Qualitative Research, 2nd ed., edited by Norman K. Denzin and Yvonne S. Lincoln. London, UK: Sage.

Schwandt, Thomas R. 1990. "Paths to Inquiry in the Social Disciplines: Scientific, Constructivist, and Critical Theory Methodologies." Pp. 258-76 in The Paradigm Dialog, edited by Egon G. Guba. London, UK: Sage.

Searle, John R. 1995. The Construction of Social Reality. London, UK: Penguin Books.

Silverman, David. 2006. Interpreting Qualitative Data: Methods for Analyzing Talk, Text and Interaction. 3rd ed. London, UK: Sage.

Silverman, David. 2010. Doing Qualitative Research: A Practical Handbook. 3rd ed. London, UK: Sage.

Stake, Robert E. 2000. “Case Studies." Pp. 435-48. in The SAGE Handbook of Qualitative Research, 2nd ed., edited by Norman K. Denzin and Yvonne S. Lincoln. London, UK: Sage.

Stake, Robert E. 2005. “Qualitative Case Studies." Pp. 443-66. in The SAGE Handbook of Qualitative Research, 2nd ed., edited by Norman K. Denzin and Yvonne S. Lincoln. London, UK: Sage.

Strauss, Anselm and Juliet Corbin. 1990. Basics of Qualitative Research: Grounded Theory Procedures and Techniques. Thousand Oaks, CA: Sage.

Strauss, Anselm and Juliet Corbin. 1998. Basics of Qualitative Research: Techniques and Procedures for Developing Grounded Theory. 2nd ed. Thousand Oaks, CA: Sage.

Suddaby, Roy. 2006. "From the Editors: What Grounded Theory Is Not." Academy of Management Journal 49 (4):633-42. doi: 10.5465/amj.2006.22083020.

Walsh, Isabelle, Judith A. Holton, Lotte Bailyn, Walter Fernandez, Natalia Levina, and Barney Glaser. 2015. "What Grounded Theory Is... A Critically Reflective Conversation among Scholars." Organizational Research Methods 18 (4):581-99. doi: $10.1177 / 1094428114565028$.

Wohfeil, Markus. 2015. "Morris B. Holbrook, Subjective Personal Introspection and the Hunger Games: A Young Researcher's Introspective Perspective.” Pp. 391-95 in Legends in Consumer Behaviour, edited by Jagdish N. Sheth. New Delhi: Sage. 
Accepted for publication in Sociological Focus published by Taylor \& Francis

(C) Victoria L. Rodner, 2019

\begin{abstract}
About the author
Victoria L. Rodner is a lecturer in marketing at the University of Stirling (UK) and a visiting scholar at the Fundação Getulio Vargas (FGV) in São Paulo, Brazil, where she carried out postdoctoral research on spiritual consumption and marketing strategies of churches. Her main areas of research include branding narratives, macromarketing, the visual arts market, emerging markets, religious consumption, institutional theory, and qualitative research methodologies with a special interest in grounded theory, constructivism and, most recently, subjective personal introspections. Her work appears in international journals including the European Journal of Marketing, Journal of Macromarketing, Nonprofit and Voluntary Sector Marketing, Arts and the Market, Marketing Intelligence and Planning, and Society.
\end{abstract}

